\title{
Penerapan Model Networked (Jejaring) dalam Pembelajaran Terpadu Pendidikan Anak Usia Dini Oleh: Halida $^{1}$
}

\begin{abstract}
Abstrak: Pembelajaran Terpadu adalah pembelajaran yang mengintegrasikan berbagai aspek dalam pembelajaran dengan menggunakan pendekatan tematik. Untuk mencapai aspek perkembangan anak dengan optimal, materi yang disampaikan dijelaskan berdasarkan tema dan subtema. Pembelajaran terpadu model networked adalah model yang memadukan berbagai pengetahuan dan keterampilan dari berbagai bidang keahlian anak, yang dijalin dalam proses kerja untuk memecahkan masalah yang diminati/dihadapi anak. Dalam model ini, anak menunjukkan proses integrasi/keterpaduan melalui pemilihan sendiri jaringan-jaringan yang dibutuhkan. Hanya anak sendirilah yang mengetahui seluk-beluk dan dimensi bidang yang diminatinya, yang dapat mencapai sumber-sumber yang dibutuhkan. Dengan demikian model networked ini, anak dilatih untuk mengembangkan minatnya, guru membimbing anak dengan petunjuk dan pengarahan yang mutakhir sehingga pembelajaran yang lebih bermakna (meaning full), menyeluruh (holistic), otentik dan aktif.
\end{abstract}

\section{Kata- kata Kunci: Model Networked (Jejaring), Pembelajaran Terpadu, Pendidikan Anak Usia Dini.}

\section{PENDAHULUAN}

Pendidikan anak usia dini (fase prasekolah) juga merupakan salah satu bentuk penyelenggaraan pendidikan yang menitikberatkan pada peletakan dasar ke beberapa arah diantaranya pertumbuhan dan perkembangan fisik, kecerdasan, sosioemosional, kepribadian, moral dan kesadaran beragama. Usia lahir sampai dengan pra sekolah merupakan masa keemasan sekaligus dengan masa kritis dalam tahapan kehidupan manusia yang akan menentukan perkembangan anak selanjutnya, masa ini merupakan masa yang tepat untuk meletakan dasar-dasar pengembangan fisik, bahasa, sosial, emosional, moral dan nilai-nilai agama, kognitif dan seni.

${ }^{I}$ Halida : adalah Dosen Jurusan Ilmu Pendidikan FKIP Untan 
Anak usia dini memiliki karakteristik yang khas, baik secara fisik, psikis, sosial, moral dan sebagainya. Masa kanak-kanak merupakan masa yang paling penting dalam hidupnya, sebab masa kanak-kanak adalah masa pembentukan pondasi dan masa kepribadian yang akan menentukan pengalaman anak selanjutnya. Sedemikian pentingnya usia tersebut maka memahami karakteristik anak usia dini menjadi mutlak dan melalui pendidikan di kelas awal perkembangan dirinya dapat dilakukan secara optimal, inilah salah satu latar belakang munculnya pembelajaran terpadu dengan pendekatan tematik model networked. Pentingnya model networked dalampembelajaran terpadu terkait dengan kehidupan nyata dan perkembangan semua aspek anak yang cenderung melihat sesuatu secara keseluruhan (holistic).

\section{PEMBAHASAN}

\section{A. Pendidikan Holistik}

Holistik berasal dari kata whole yang berarti menyeluruh. Pendidikan merupakan suatu bentuk pendidikan yang bertujuan untuk membangun seluruh dimensi manusia, yaitu untuk membangun seluruh dimensi manusia, yaitu dimensi sosial, emosional, motorik, akademik, spritual dan kognitif sehingga membentuk insan kamil.

Saat ini, trend pendidikan internasional juga mengarah pada pendidikan holistik sebenarnya secara eksplisit telah dituangkan dalam Undang-undang Sistem Pendidikan Nasional Republik Indonesia (UU Sisdiknas No. 20/2003), yaitu pada Bab II Pasal 3 yang berbunyi "Pendidikan Nasional berfungsi mengembangkan kemampuan dan membentuk watak serta peradaban bangsa yang bermartabat dalam rangka mencerdaskan kehidupan bangsa, dan bertujuan untuk berkembangnya potensi peserta didik agar berakhlak mulia, sehat, berilmu, cakap, kreatif, mandiri dan menjadi warga negara yang demokratis serta bertanggung jawab.

Dalam kesepakatan Education 2000: A Holistic Perspective disimpulkan bahwa tujuan pendidikan holistik adalah:

1. Mengajarkan anak dengan kesadaran penuh bahwa setiap aspek dalam kehidupan saling terkait.

2. Mendidik seluruh aspek perkembangan anak.

3. Menghargai bahwa setiap manusia mempunyai kelebihan masingmasing sehingga tidak dapat disamakan. 
4. Mendidik anak untuk berpikir secara holistik yang mencakup intuisi, konstekstual, kreativitas, dan aspek fisik.

5. Memberikan lingkungan pembelajaran yang kondusif.

6. Menggunakan kurikulum holistik yang mengintegrasikan komunitas dengan perspektif global.

Adapun perkembangan holistik anak usia dini seperti terlihat pada gambar di bawah ini:

Gambar 1.1 Perkembangan Holistik Anak Usia Dini

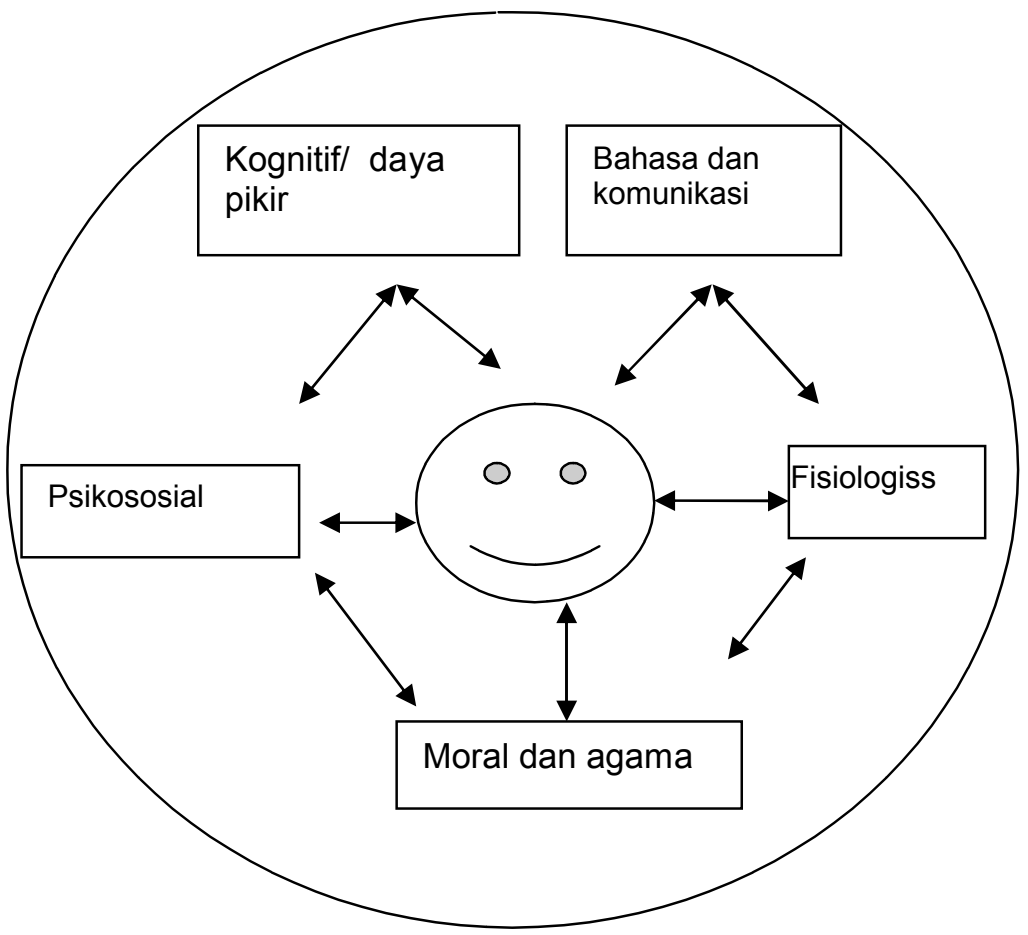

Dari gambar di atas terlihat bahwa antara satu aspek perkembangan dengan aspek yang lain saling berkaitan dalam proses pembelajaran. Perkembangan anak usia dini secara holistik tidak parsial dan terpisah.

\section{B. Pembelajaran Terpadu Anak Usia DIni}

Model pembelajaran terpadu merupakan salah satu model implementasi kurikulum yang dianjurkan untuk diaplikasikan pada 
semua jenjang pendidikan, mulai dari tingkat Taman Kanak-Kanak sampai SMA. Model pembelajaran ini pada hakikatnya merupakan suatu pendekatan pembelajaran yang memungkinkan peserta didik baik secara individual maupun kelompok aktif mencari, menggali, dan menemukan konsep serta prinsip secara holistik dan otentik. Pembelajaran ini merupakan model yang mencoba memadukan beberapa pokok bahasan. (Puskur Balitbang)

Pembelajaran terpadu menunjukkan bahwa model pembelajaran terpadu sejalan dengan beberapa aliran modern yaitu termasuk dalam aliran pendidikan progresivisme. Aliran pendidikan progresivisme memandang pendidikan yang mengutamakan penyelenggaraan pendidikan di sekolah berpusat pada anak (student centered), sebagai reaksi terhadap pelaksanaan pendidikan yang masih berpusat pada guru (teacher centered) dan pada bahan ajar. Tujuan utama sekolah adalah untuk meningkatkan kecerdasan praktis, serta untuk membuat anak lebih efektif dalam memecahkan berbagai problem yang disajikan dalam konteks pengalaman (experience) pada umumnya (William F.Oneill, 1981).

Pembelajaran terpadu diawali dari suatu pokok bahasan atau tema tertentu yang dikaitkan dengan pokok bahasan lainnya, dimana konsep tertentu dikaitkan dengan konsep lain direncanakan, baik dalam satu bidang atau lebih dan dengan beragam pengalaman belajar agar pembelajaran menjadi lebih bermakna. (Hadisubroto, 1998). Dengan adanya pemaduan ini anak akan memperoleh pengetahuan dan keterampilan secara utuh sehingga pembelajaran lebih bermakna (meaningfull) bagi siswa. Bermakna disini memberi arti bahwa dalam pembelajaran terpadu siswa akan dapat memahami konsep- konsep yang mereka pelajari melalui pengalaman langsung dan nyata yang menghubungkan antar konsep dalam intra mata pelajaran maupun antar pelajaran. Jika dibandingkan dengan pendekatan konvensional, maka pembelajaran terpadu tampak lebih menekankan pada keterlibatan siswa dalam belajar, sehingga siswa tampak aktif terlibat dalam proses pembelajaran untuk pembuatan keputusan (decision 
making). (Sukayati 2004:4).Oleh sebab itu, pembelajaran terpadu tidak dapat melepaskan diri dari kegiatan pembelajaran yang sistematik, seperti digambarkan di dalam diagram di bawah ini.

\section{Pembelajaran Terpadu dalam Bingkai Sistem Pembelajaran}

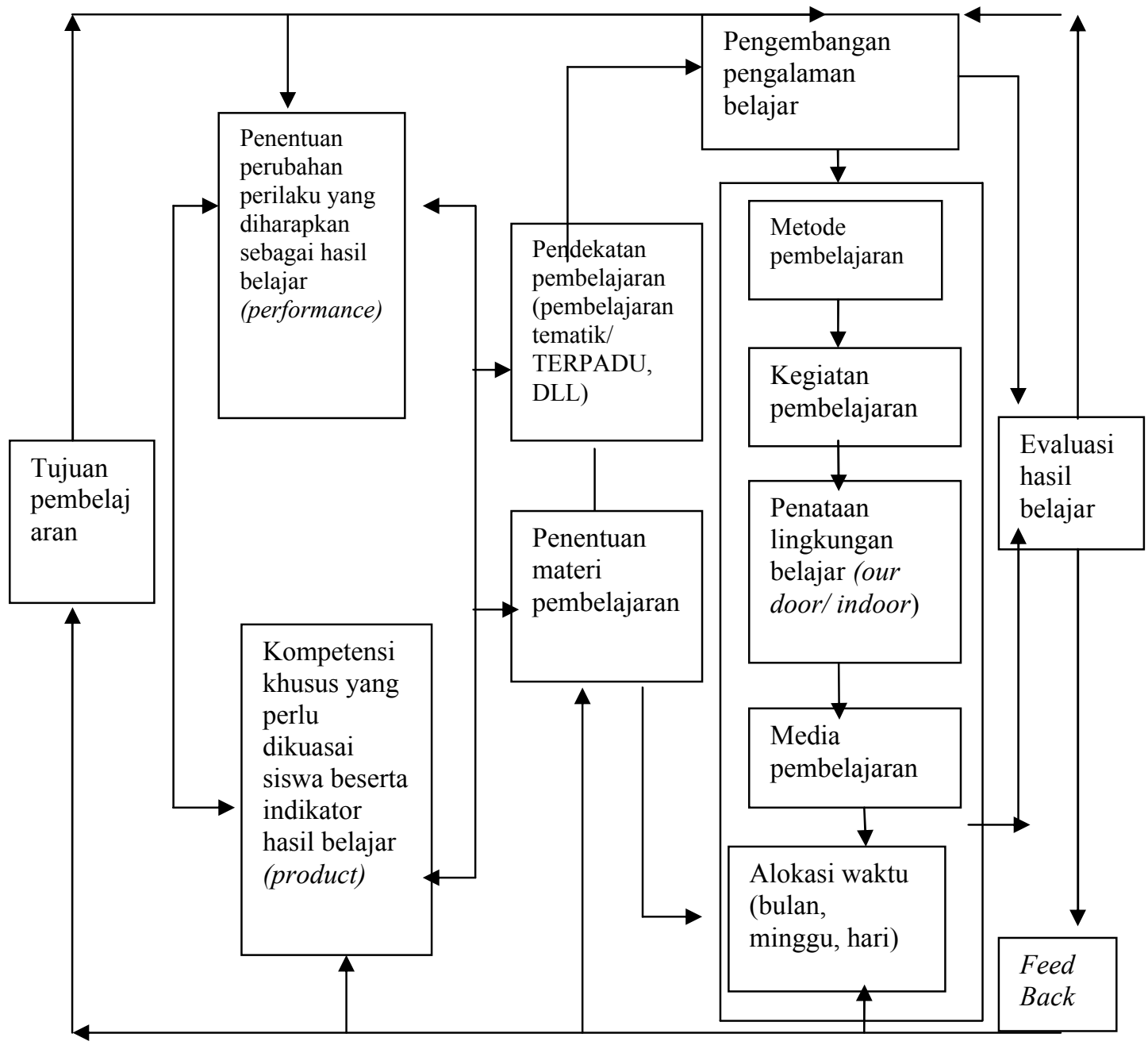

Sumber: Martini Jamaris, Pengembangan Holistik Anak Usia Dini Berbasis Kurikulum dan Pembelajaran Terpadu (2009:3) 
Dengan demikian pembelajaran terpadu merupakan suatu kegiatan yang bersifat sistematis, artinya bahwa pembelajaran merupakan suatu kegiatan yang terdiri dari berbagai komponen seperti: tujuan pembelajaran, isi dan materi pembelajaran, pengalaman pembelajaran mencakup metode pembelajaran, media, alokasi waktu dan tempat pembelajaran, serta evaluasi hasil pembelajaran, perlu dirancang secara sistematis dan sistemik, agar segala usaha pembelajaran dapat dilakukan secara efektif dan efesien. (Martini Jamaris, 2009). Oleh karena pembelajaran terpadu merupakan salah satu pendekatan yang digunakan di dalam pembelajaran yang menekankan pada perencanaan dan pelaksanaan pembelajaran secara holistik, berdasarkan desain kurikulum terpadu yang direncanakan.

\section{Aplikasi Model Networked pada Pembelajaran Terpadu AUD}

Model networked adalah model yang memadukan berbagai pengetahuan dan keterampilan dari berbagai bidang keahlian, yang dijalin dalam proses kerja untuk memecahkan masalah yang diminati/dihadapi.

\section{Pengertian Model Networked.}

Model networked pada pembelajaran terpadu adalah suatu sumber tenaga/input yang terus menerus, yang senantiasa menyediakan bermacam ide baru, diperluas, dan diramalkan kemungkinannya atau di perhalus/disaring. Jaringan profesional pembelajar biasanya tumbuh dalam arah yang jelas, dan kadang tidak terlalu jelas. Dalam mencari pengetahuan, dalam model ini dikatakan bahwa pebelajar bergantung pada jaringan profesional tersebut sebagai sumber informasi primer yang harus mereka sharing melalui keahlian dan minat mereka sendiri.

Dalam model ini, tidak seperti model-model yang lain, anak menunjukkan proses integrasi/keterpaduan melalui pemilihan sendiri jaringan-jaringan yang dibutuhkan. Hanya anak sendirilah yang mengetahui seluk-beluk dan dimensi bidangnya, yang dapat mencapai sumber-sumber yang dibutuhkan. Model ini, tidak seperti yang lain, tumbuh dan berkembang sepanjang waktu seraya mendorong anak melalui bimbingan atau petunjuk-petunjuk baru. 


\section{Bentuk Model Networked.}

Model networked terdengar seperti suatu conference call melalui tiga atau empat arah yang menyediakan berbagai kesempatan beresplorasi dan memberikan penjelasan. Walaupun bermacam-macam ide ini mungkin tidak datang semua dalam satu waktu, anak terbuka terhadap berbagai mode input atau masukan yang majemuk ketika komponen-komponen divergen disaring dan dimulai agar sesuai dengan kebutuhan. Model ini tampak seperti jaringan berita yang terekam dalam gambar dan cerita dari seluruh dunia. Model ini seperti sinyal cahaya satelit di sana sini dan menerima sinyal dari manapun.

\section{Kelebihan Model Networked.}

Banyak kelebihan dari model ini. Pendekatan pembelajaran terpadu ini secara alami sangat proaktif, dengan inisiatif pembelajar sendiri mencari-cari dan mengikuti ide-ide baru yang muncul. Pebelajar distimulasi dengan informasi yang relevan, keterampilan atau konsep-konsep yang akan dilakukannya nanti. Akan tetapi, kelebihan model ini tidak dapat dipaksakan pada pebelajar, tetapi harus diberikan dari dasar dahulu. Namun demikian, mentor dapat menyediakan model-model yang dibutuhkan untuk mendukung tahaptahap pembelajaran yang kompleks.

\section{Kelemahan Model Networked.}

Kekurangan model ini telah diketahui oleh orang yang telah mengembangkan berbagai macam minat demi kegiatan yang disukai anak. Sangat mudah terjadi bentrokan antara ide yang satu dengan ide yang lain. Model ini juga memungkinkan untuk memperoleh lebih dari yang kita pikirkan. Ide-ide tertentu tampak menarik dan bermanfaat, namun tiba-tiba jadi terlalu banyak. Hal ini mengkibatkan manfaatnya tidak lagi lebih banyak dari jerih payah yang telah dibuat. Kelemahan lainnya dari model ini adalah, jika dilakukan dengan ekstrem, dapat menyebabkan minat menjadi lemah dan mencairkan semangat mental anak. 


\section{Penerapan Model Networked pada Pendidikan Anak Usia Dini}

Model ini, seperti model immersed, sering kali memindahkan beban tanggung jawab keterpaduan/integrasi ke anak daripada ke perancang pembelajaran. Akan tetapi, model ini merupakan model yang tepat dihadirkan untuk anak yang telah termotivasi. Guru sering kali menyajikan jaringan/networking untuk memperluas cakrawala anak dengan memberikan perspektif yang dibutuhkan. Ketika jaringan tersusun, sambungan yang baik muncul sepanjang jalinan tersebut. Sering kali, temuan yang tidak disengaja ini menggerakkan lebih dalam kepada anak terhadap bidang yang digeluti atau secara nyata justru menghasilkan penciptaan bidang-bidang yang lebih spesifik. Bidang yang diciptakan tersebut benar-benar merupakan hasil dari keahlian anak yang "terlarut".

\section{Langkah-langkah dalam Mengembangkan Model Networked sbb:}

a. Analisis Perkembangan Anak Usia Dini.

b. Tentukan konten kurikulum berdasarkan perkembangan anak, dengan membuat Standar Kompetensi, Kompetensi Dasar, Indikator dan Hasil Belajar.

c. Buat Rancangan kegiatan Mingguan (RKM).

d. Tentukan tema dan subtemanya, kaitkan dengan aspek-aspek perkembangan anak.

e. Kemudian tentukan indikator yang akan dikembangkan disetiap aspek kemampuan.

f. Desain model networked, lalu masukkan minat-minat anak sesuai dengan aspek perkembangan anak.

g. Hasil dari rancangan model networked dimasukkan dalam Rancangan Kegiatan Harian dengan berpijak pada tema dan subtema.

h. Tentukan media, fasilitas, strategi, pendekatan maupun metode langkah-langkah kegiatan dalam pelaksanaan, (Pembukaan, Kegiatan Inti, Penutup).

i. Lakukan evaluasi terhadap kegiatan tersebut dengan menggunakan RKH yang telah dibuat. 
Contoh Model Networked dalam Pembelajaran Terpadu Anak Usia Dini, Aspek perkembangan yang dikembangkan adalah sosial emosianal, bahasa, kognitif dan motorik, seperti pada tabel di bawah ini

\section{Tema : Negaraku}

Subtema : Hari Kemerdekaan RI (Memperingari hari 17 Agustus)

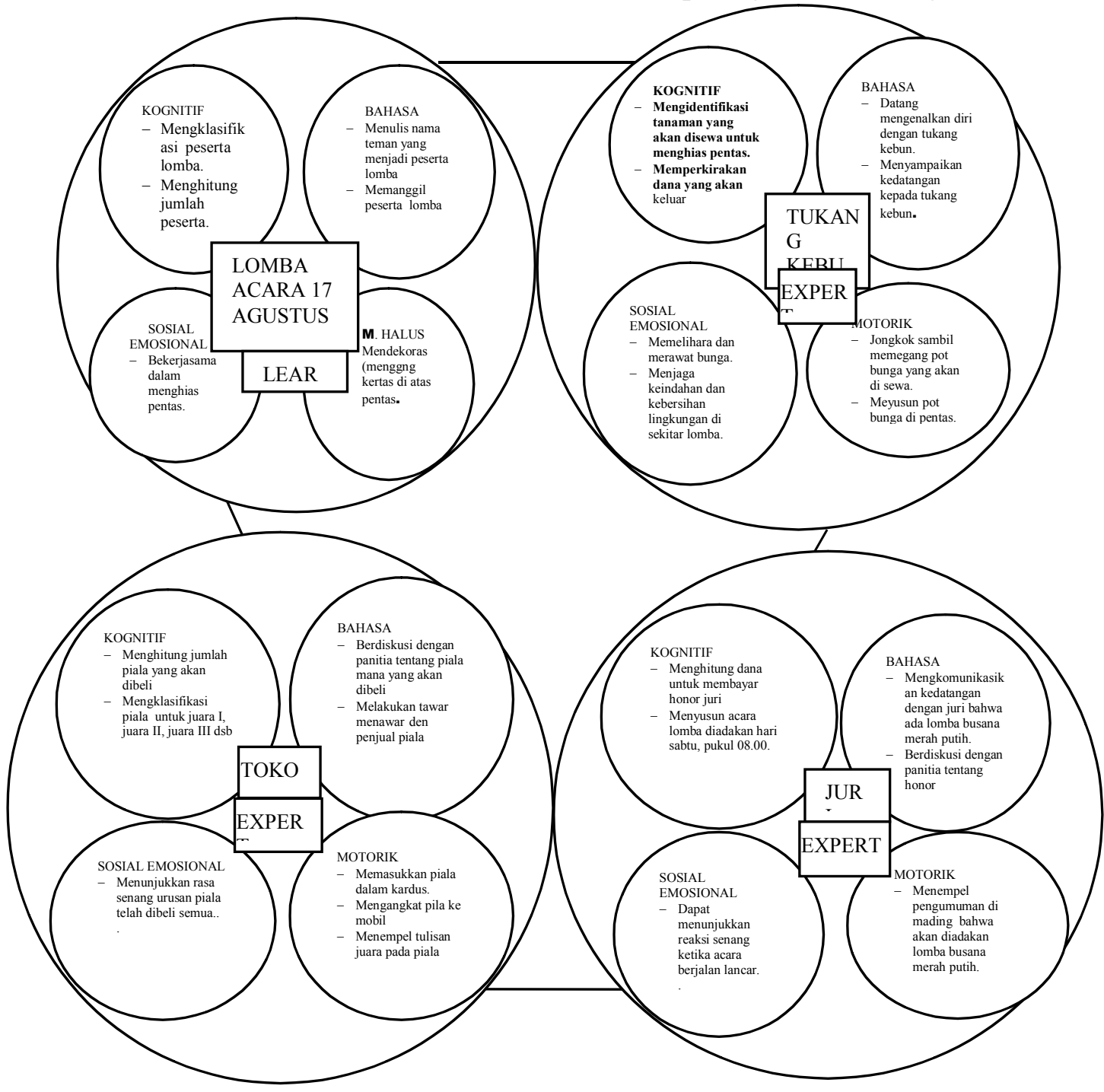


Pada Pendidikan Anak Usia Dini pembelajaran menekankan semua aspek perkembangan anak secara menyeluruh (holistic) melalui pendekatan tematik. Salah model dalam pembelajaran terpadu yang juga menekankan semua aspek perkembangan berdasarkan minat adalah model networked. Pembelajaran terpadu model networked adalah model yang memadukan berbagai pengetahuan dan keterampilan dari berbagai bidang keahlian anak, yang dijalin dalam proses kerja untuk memecahkan masalah yang diminati/dihadapi anak. Pembelajaran terpadu model networked ini secara alami sangat proaktif, dengan inisiatif pembelajar sendiri mencari-cari dan mengikuti ide-ide baru yang selalau muncul. Pebelajar distimulasi dengan informasi yang relevan, keterampilan atau konsep-konsep yang akan dilakukannya. Model networked ini, anak dapat mengintegrasikan atau memadukan minatnya sendiri sesuai dengan jaringan-jaringan yang dibutuhkan. Pembelajaran berpusat pada anak (student centered). Hanya anak sendirilah yang mengetahui seluk-beluk dan dimensi bidang yang diminatinya. Model networked ini, anak dilatih untuk mengembangkan minatnya sesuai dengan potensi yang dimiliki, guru hanya sebagai motivator dan fasilitator.

\section{DAFTAR PUSTAKA}

Catron E.Carol and Jan Allen. Early Childhood Curriculum. New Jersey: Prentice Hall Inc, 1999.

Departemen Pendidikan Nasional, Kurikulum TK (Pedoman Penyusunan

Silabus) Dikdasmen, Direktorat Pendidikan TK dan SD, 2004.

Dodge, Diane Trister, and Laura J. Colker, The Creative Curriculum for

Preschool, Third Edition, Teaching Strategis, Washington: DC, 2001.

Dodge, Diane Trister, Laura J. Colker, and Cate Heromen, The Creative Curriculum for Preschool, Fourth Edition, Teaching Strategis, Washington, DC, 2005.

Fogarty, Robin, The Mindfull School How to Integrate the Curricula, United States of America:IRI Skylight Training and Publishing, Inc.1991. 
Gunarti, Winda, Lilis Suryani, Azizah Muis, Metode Pengembangan Perilaku dan Kemampuan Dasar Anak Usia Dini, Jakarta: UT, 2010.

Jamaris, Martini , Perkembangan dan Pengembangan Anak Usia Taman kanak Kanak, Jakarta, Grasindo Gramedia Widiasarana Indonesia, 2006.

Jamaris, Martini, Pengembangan Holistik Anak Usia Dini Berbasis Kurikulum dan Pembelajaran Terpadu (Makalah, 2009).

Kostelnik, Marjorie J, et al, Developmentally Apropriate Curriculum: Best Practices in Early Childhood Education. USA. Prentice Hall. Inc, 1991.

Sabda, Syaifuddin, Model Kurikulum Terpadu IPTEK dan IMTAQ, Quantum Teaching, Jakarta, 2006.

Soemiarti Patmonodewo, Pendidikan Anak Prasekolah, Jakarta: Rineka Cipta, 2003.

Sukayati, Pembelajaran Tematik di SD Awal Merupakan Terapan dari Pembelajaran Terpadu, Yogyakarta: PPPG Matematika, Ditjen Dikdasmen Depdikbud, 2004. 